\title{
Antimicrobials in Gynaecological Practice
}

\author{
Patabendige $\mathrm{M}^{\mathrm{a}}$ Herath RP ${ }^{\mathrm{b}}$, Wijesooriya WRPLI ${ }^{\mathrm{c}}$
}

\begin{abstract}
Surgical site infections are a common complication of Gynaecological surgeries. Up to $8-10 \%$ of Gynaecological patients undergoing an operative procedure will develop a surgical site infection. In surgeries with high rates of post-operative infection, antibiotic prophylaxis can play a major role in improving outcomes. In addition there are many indications where antimicrobial treatment is necessary in day-to-day Gynaecological practice. This review summarizes the available medical literature to assess the indications and appropriate antimicrobials for common circumstances in Gynaecological practice.
\end{abstract}

Key Words: Antibiotic use, Gynaecological surgery, surgical site infection.

\section{INTRODUCTION}

Out of all patients undergoing Gynaecological surgery $8-10 \%$ would develop surgical site infections, which have shown to increase morbidity and mortality, readmission, increase health care cost and length of hospital stay ${ }^{1}$. Appropriate and timely antibiotic prophylaxis has shown to be highly effective in reducing the incidence of surgical site infections ${ }^{3}$.Other factors to consider when choosing an appropriate antibiotic for prophylaxis include low toxicity, an established safety record, cost and the ability to reach an effective concentration in the relevant tissue prior to the procedure and local epidemiology

${ }^{a}$ Registrar in Obstetrics and Gynaecology, University Obstetrics and Gynaecology Unit, Teaching Hospital, Mahamodara, Galle, Sri Lanka.

${ }^{b}$ Senior Lecturer in Obstetrics and Gynaecology, Department of Obstetrics and Gynaecology, Faculty of Medicine, University of Kelaniya, Ragama, Sri Lanka.

c Senior Lecturer in Microbiology, Department of Microbiology, Faculty of Medicine, University of Kelaniya, Ragama, Sri Lanka.

Correspondence: Dr. Malitha Patabendige MBBS

Email-mpatabendige@gmail.com

(D) http://orcid.org/0000-0002-4092-7092.

Competing interests: The authors report no conflict of interest of causative agents and their resistant patterns ${ }^{4}$. Though antibiotic prophylaxis or empirical antibiotic therapy is based on above facts, the antibiotic regimens should always be adjusted as per culture results and antibiotic sensitivity pattern of the samples collected when relevant.

This article summarizes current recommended practice of antimicrobial use in Gynecological practice according to the available evidences and guidelines. The objective of this article is to provide a guide on the use of antimicrobials in Gynaecological practice.

\section{ABDOMINAL HYSTERECTOMY}

This is a clean, contaminated surgery and single course of prophylactic antibiotics is recommended ${ }^{5}$. The benefit of antibiotic prophylaxis in reducing postoperative infection is well established for both vaginal and abdominal hysterectomy ${ }^{6,7}$. It should be noted that randomized trials of antibiotic prophylaxis for laparoscopic total hysterectomy and laparoscopically assisted hysterectomy have not yet been performed ${ }^{8}$. Bacterial vaginosis is a risk factor for infection after hysterectomy. A randomized non-blinded controlled trial found that treatment with rectal metronidazole for women with bacterial vaginosis significantly reduced the rates of vaginal cuff infection post hysterectomy ${ }^{9}$. The available evidence suggests that all patients should be screened and treated for bacterial vaginosis prior to undergoing hysterectomy. Patients should receive antibiotic prophylaxis for hysterectomy including an antibiotic with an anaerobic coverage. Multiple doses of antibiotic are not more effective than a single antibiotic dose prior to incision ${ }^{10}$.

Primary therapy includes single dose of cefuroxime $1.5 \mathrm{~g}$ (intravenous) IV and metronidazole 500mg IV ${ }^{5,8}$. Alternative therapies are a combination of gentamicin 4-6mg/kg IV and metronidazole 500mg IV or a single dose of co-amoxiclav 1.2g IV. If there is a history of pelvic inflammatory disease or suspected sexually transmitted infections add oral doxycycline $100 \mathrm{mg}$ at least one hour prior to surgery followed by $200 \mathrm{mg} 6$ hours after the procedure ${ }^{5}$.

In addition to antibiotic prophylaxis, it is essential to look for all factors that affect the infectious risk. Adherence to appropriate skin preparation procedure, including hair clipping as opposed to shaving by razors, and effective antisepsis of both patient and staff are required ${ }^{11}$. Sterile surgical fields must be ensured, and ongoing quality assessment of sterilization technique, air ventilation, and postoperative wound care is needed. Consistent infection control surveillance and reporting of infectious complications can minimize these morbidities and possibly to identify clusters of infection and the emergence of antibiotic resistant organisms. This will dictate changes to operative routines and to respond to evolving microbial diversity that seems inevitable.

\section{EVACUATION OF RETAINED PRODUCTS OF CONCEPTION}

Primary therapy is a single dose of cefuroxime $1.5 \mathrm{~g}$ IV and metronidazole $500 \mathrm{mg}$ IV combination or else a single dose of co-amoxiclav $1.2 \mathrm{~g}$ IV 5 . Alternative treatment option includes a 
single dose of clindamycin $600 \mathrm{mg}^{\mathrm{IV}}{ }^{5}$. However, prophylactic antibiotics are not recommended for medical termination of pregnancy ${ }^{8}$.

\section{BACTERIAL VAGINOSIS}

Primary therapy is oral metronidazole $400 \mathrm{mg} 12$ hourly for 7 days ${ }^{12}$. Alternative treatment options are metronidazole gel $0.75 \%$, one full applicator $(5 \mathrm{~g})$ intravaginally, once a day for 5 days or clindamycin cream $2 \%$, one full applicator $(5 \mathrm{~g})$ intravaginally at bedtime for 7 days $^{13}$.

\section{SEPTIC MISCARRIAGE}

Primary therapy is a combination of cefuroxime $750 \mathrm{mg}$ IV 8 hourly and metronidazole 500mg IV 8 hourly with or without gentamicin $5-7 \mathrm{mg} / \mathrm{kg}$ IV once daily ${ }^{5}$. Co-amoxiclav1.2g IV 8 hourly and gentamicin $5 \mathrm{mg} / \mathrm{kg}$ IV once daily is another option. Add doxycycline if sexually transmitted infection is suspected ${ }^{5}$. Alternative therapy is ceftriaxone $2 \mathrm{~g}$ IV daily and metronidazole 500mg IV 8 hourly or else clindamycin $600 \mathrm{mg}$ IV 8 hourly and gentamicin $5-7 \mathrm{mg} / \mathrm{kg}$ IV once daily ${ }^{5}$. Add doxycycline if sexually transmitted infection is suspected ${ }^{5}$.

\section{PELVIC INFLAMMATORY DISEASE OUTPATIENT REGIMEN- FOR MILD TO MODERATE DISEASE}

Primary therapy is ceftriaxone $500 \mathrm{mg}$ intramuscular (IM) single dose and oral doxycycline 100mg 12 hourly for 14 days and oral metronidazole 400mg 12 hourly for 14 days ${ }^{5,14}$. Alternative therapy (in pregnancy) includes ceftriaxone $500 \mathrm{mg}$ IM single dose with oral azithromycin $1 \mathrm{~g}$ single dose and oral metronidazole $400 \mathrm{mg}$ 12 hourly for 14 days ${ }^{5,13,14}$. Contact tracing and treatment is indicated in all patients ${ }^{5}$.

If the etiology is of non-sexually acquired, another option is oral co-amoxiclav $625 \mathrm{mg} 8$ hourly and oral doxycycline $100 \mathrm{mg} 12$ hourly with oral metronidazole 400mg 12 hourly for 14 days ${ }^{5}$. Oral azithromycin $1 \mathrm{~g}$ single dose can be given instead of doxycycline ${ }^{5,13}$.

\section{INPATIENT REGIMEN- FOR SEVERE DISEASE}

Clinical experience should guide decisions regarding transition to oral therapy, which usually can be initiated within 24-48 hours of clinical improvement ${ }^{13}$. In women with tubo-ovarian abscesses, at least 24 hours of inpatient observation is recommended 13. Primary therapy is ceftriaxone $1 \mathrm{~g}$ IV daily with oral doxycycline $100 \mathrm{mg} 12$ hourly and oral metronidazole 400mg 12 hourly for 14 days ${ }^{5}$. However, when tuboovarian abscess is present, clindamycin ( $450 \mathrm{mg}$ orally 6 hourly) or metronidazole (500 mg twice daily) should be used to complete at least 14 days of therapy with doxycycline to provide more effective anaerobic coverage than doxycycline alone ${ }^{13}$. Alternative treatment option is co-amoxiclav $1.2 \mathrm{~g}$ IV 8 hourly with ciprofloxacin 400mg IV 12 hourly and metronidazole $500 \mathrm{mg}$ IV 12 hourly. Therapy should be continued at least for total of 14 days and switch to oral therapy with clinical improvement ${ }^{5}$.

\section{VAGINAL CANDIDIASIS ACUTE UNCOMPLICATED VAGINAL CANDIDIASIS}

Primary therapy includes topical clotrimazole pessary $500 \mathrm{mg}$ single dose at night or clotrimazole pessary $200 \mathrm{mg}$ for three nights $100 \mathrm{mg}$ for six nights or else clotrimazole $10 \%$ cream $5 \mathrm{~g}$ intravaginally stat ${ }^{5,13}$. Miconazole 100 mg vaginal suppository, one suppository daily for 14 days can also be given ${ }^{13}$. Alternative treatment options are oral fluconazole $150 \mathrm{mg}$ single dose or else oral itraconazole 200mg 12 hourly 2 doses ${ }^{5,13}$. Oral therapy is indicated when intolerant to topical treatment, severe infection or recurrent infection ${ }^{5}$. During pregnancy oral therapy should be avoided. Need to treat symptomatic partners as well.

\section{RECURRENT VAGINAL CANDIDIASIS}

If there are four or more episodes occurring per year oral therapy is preferred ${ }^{13}$. Fluconazole $150 \mathrm{mg}$ weekly for six months is recommended ${ }^{5}$. Recommendation is a longer duration of initial therapy (e.g., $7-14$ days of topical therapy or a $100 \mathrm{mg}$, $150 \mathrm{mg}$ or $200 \mathrm{mg}$ oral dose of fluconazole every third day for a total of three doses; Day 1, 4, and 7) to attempt mycologic remission before initiating a maintenance antifungal regimen ${ }^{13}$. Oral fluconazole (i.e., $100 \mathrm{mg}, 150 \mathrm{mg}$ or $200 \mathrm{mg}$ dose) weekly for six months is the first line maintenance regimen ${ }^{13}$. If this regimen is not feasible, topical treatments used intermittently can also be considered ${ }^{13}$.
The women need to have high vaginal swab for culture, as certain non-albicans Candida spp are developing resistance to azoles ${ }^{5,13}$.

\section{POST-OPERATIVE WOUND INFECTIONS AFTER ABDOMINAL SURGERIES}

Recommended regimen is doxycycline $100 \mathrm{mg}$ orally twice a day for 21 days $^{13}$. Alternative regimen is Erythromycin base $500 \mathrm{mg}$ orally four times a day for 21 days $^{13}$.

\section{NON-GONOCOCCAL CERVICITIS}

Primary therapy is azithromycin $1 \mathrm{~g}$ single dose or else doxycycline $100 \mathrm{mg} 12$ hourly for 7 days $^{13}$.

\section{SYPHILIS}

\section{EARLY SYPHILIS (PRIMARY, SECONDARY AND EARLY LATENT)}

Primary therapy is benzathine penicillin 2.4MU IM single dose ${ }^{13}$. Data to support use of alternatives to penicillin in the treatment of primary and secondary syphilis are limited ${ }^{13}$. Alternatively doxycycline $100 \mathrm{mg} 12$ hourly for 14 days or tetracycline 500mg 6 hourly for 14 days, can be given to women with penicillin allergy ${ }^{13}$. Azithromycin as a single $2 \mathrm{~g}$ oral dose has been effective for treating primary and secondary syphilis in some populations ${ }^{13}$.

\section{LATE SYPHILIS (LATE LATENT SYPHILIS, SYPHILIS OF UNKNOWN DURATION, GUMMATOUS SYPHILIS AND CARDIOVASCULAR SYPHILIS)}

Primary therapy is benzathine penicillin 2.4 MU IM weekly for 3 weeks ${ }^{13}$. Alternative therapy includes doxycycline $100 \mathrm{mg} 12$ hourly for 28 days or tetracycline $500 \mathrm{mg}$ 6 hourly for 28 days and these regimes can be used in penicillin allergy ${ }^{13}$. The effectiveness of alternatives to penicillin in the treatment of latent syphilis has not been well documented ${ }^{13}$ 


\section{NEUROSYPHILIS}

Primary therapy is benzathine penicillin 4 MU IV every 4 hourly for 14 days ${ }^{13}$. Alternative therapy is procaine penicillin G 2.4 MU IM once daily and probenecid $500 \mathrm{mg}$ orally four times a day for 14 days ${ }^{13}$.

\section{TRICHOMONASIS}

Primary therapy is metronidazole $2 \mathrm{~g}$ orally in a single dose or tinidazole $2 \mathrm{~g}$ orally in a single dose ${ }^{13}$. Alternative therapy includes metronidazole $400 \mathrm{mg}$ orally twice a day for 7 days ${ }^{13}$.

\section{OTHER COMMON GYNAECOLOGICAL PROCEDURES}

Antibiotic prophylaxis is not recommended for insertion of intrauterine contraceptive devices, hysteroscopy, diagnostic laparoscopy and laparoscopic sterilization ${ }^{4,5}$. Furthermore antibiotic prophylaxis is not recommended for hysterosalpingography (HSG) without a prior history of pelvic inflammatory disease ${ }^{4,5}$. Infection after HSG occurs in a small number of women and reported rates are $1.4-3.4 \%{ }^{25}$. It is also not recommended in Large Loop Excision of Transformation
Zone (LLETZ) ${ }^{26}$. A recent Dutch study on hysteroscopy conducted in an outpatient setting in asymptomatic women with infertility found an infection rate of $0.4 \%$ without antibiotic prophylaxis ${ }^{27}$.

However, based on above studies antibiotic prophylaxis should be instituted in any of the procedures mentioned above if there is a reason to suspect infection risk or if the findings at the procedure indicate risk of infection e.g. dilated fallopian tubes at HSG and a history of PID ${ }^{28}$. Doxycycline is the usual recommended agent and is continued for five days to treat presumed PID. Single-dose azithromycin is an acceptable alternative ${ }^{8}$. There is debate on the value of routine prophylactic antibiotics for midurethral sling procedures for urinary incontinence due to lack of evidence to give a recommendation ${ }^{29}$. Broad spectrum antibiotics should be used during major abdominal, laparoscopic or vaginal procedures ${ }^{28}$.

\section{AUTHORS \\ CONTRIBUTIONS}

MP designed and wrote the paper. Both RPH and WRPLIW contributed for editing the paper. All authors accepted the final version to be published.

\section{Table 1: Strategies to prevent laparoscopic port site infections.}

Strategies to prevent laparoscopic port site infections

1. Use of disposable trocars and instruments

2. Adequate availability of properly sterilised reusable trocars to cover all the surgical procedures in a day.

3. Use of autoclavable laparoscopic hand instruments.

4. Use of instruments with good ergonomics, limited joints and facility for proper cleaning of the debris collected in its crevices.

5. A proper cleaning of the instrument is best achieved by ultrasonic technology.

6. Use of autoclaved water for cleaning the instruments after dismantling.

7. Proper guidelines should be followed regarding the concentration, contact time and cycles of use for instrument sterilization with liquid sterilizing agents.

8. Use of plasma sterilizer or ethylene oxide in between the consecutive surgery for instrument sterilization.

9. Avoiding inter-departmental sharing of instruments, such as using instruments used for gynecological or urological procedures.

10. Avoiding spillage of bile or gut content in the operative area or the port site.

11. Use of non-porous specimen retrieval bags for retrieving the specimen.

12. Thorough irrigation and cleaning of the port site before wound closure.

\section{CONFLICTS OF INTEREST AND FINANCIAL DISCLOSURE}

There are no conflicts of interest and no relevant sources of funding.

\section{REFERENCES}

1. Kamat AA, Brancazio L, Gibson $M$. Wound infection in gynecologic surgery. Infect Dis Obstet Gynecol. 2000; 8: 230-234.

2. Kenyon S, Pike K, Jones DR, et al. Childhood outcomes after prescription of antibiotics to pregnant women with spontaneous preterm labour: 7-year follow-up of the ORACLE II trial. Lancet. 2008; 372:1319-1327.

3. Steinberg JP, Braun BI, Hellinger WC et al. Timing of antimicrobial prophylaxis and the risk of surgical site infections: results from the Trial to Reduce Antimicrobial Prophylaxis Errors. Ann Surg 2009; 250: 10-16.

4. ACOG Committee on Practice Bulletins-Gynecology. ACOG practice bulletin No. 104: antibiotic prophylaxis for gynecologic procedures. Obstet Gynecol 2009; 113: 1180-1189.

5. Sri Lanka College of Microbiologists. Empirical and Prophylactic Use of Antimicrobials: National Guidelines 2016. Available at: http://slmicrobiology. net/antibiotic-guidelines-2016/. Accessed on 04 Nov 2017.

6. Duff P, Park RC. Antibiotic prophylaxis in vaginal hysterectomy: a review. Obstet Gynecol. 1980; 55: 193-202.

7. Tanos V, Rojansky N. Prophylactic antibiotics in abdominal hysterectomy. J Am Coll Surg. 1994; 179: 593-600.

8. Clifford V, Daley A. Review article. Antibiotic prophylaxis in obstetric and gynaecology procedures: A Review. Aust New Z J Obstet Gynae 2012; 52: 412-19.

9. Larsson PG, Carlsson B. Does preand postoperative metronidazole treatment lower vaginal cuff infection rate after abdominal hysterectomy among women with 
bacterial vaginosis? Infect Dis Obstet Gynecol 2002; 10: 133-140.

10. Chang WC, Lee MC, Yeh LS et al. Quality-initiated prophylactic antibiotic use in laparoscopicassisted vaginal hysterectomy. Aust N Z J Obstet Gynaecol 2008; 48: 592-595.

11. Tanner J, Norrie P, Melen K. Preoperative hair removal to reduce surgical site infection. Cochrane Database Syst Rev. 2011. 9;(11):CD004122.

12. Shah AK, Gambhir RP, Hazra N, Katoch..Non tuberculous mycobacteria in surgical wounds- a rising cause of concern? R Indian J Surg. 2010; 72(3):206-10.

13. Workowski KA, Bolan GA; Centers for Disease Control and Prevention. Sexually transmitted diseases treatment guidelines, 2015. MMWR Recomm Rep. 2015; 5(64) (03):1137.

14. Clinical Effectiveness Group British Association for Sexual Health and HIV. UK National Guideline for the Management of Pelvic Inflammatory Disease; 2011.

15. Horan TC, Gaynes RP, Martone WJ, et al. CDC definitions of nosocomial surgical site infections, 1992: a modification of CDC definitions of surgical wound infections. Infection Control and Hospital Epidemiology. 1992;13: 606-8.

16. National Institute for Health and Clinical Excellence. NICE Clinical Guideline 74. Surgical site infections: prevention and treatment of surgical site infection. Oct 2008. Updated Feb 2017.
17. Noorani HZ, Adams E, Glick S, et al. Future Research Needs Papers, No. 40. Rockville: Agency for Healthcare Research and Quality (US); 2013 Jun.

18. Royal College of Obstetricians and Gynaecologists. Cervical Cerclage. Green-top Guideline No. 60; 2011.

19. Sasmal PK, Mishra TS, Rath S, Meher S, Mohapatra D. Port site infection in laparoscopic surgery: A review of its management. World $\mathrm{J}$ Clin Cases 2015; 3(10): 864-871.

20. Rutala WA, Weber DJ. Disinfection and sterilization in health care facilities: what clinicians need to know. Clin Infect Dis. 2004 1; 39(5):702-9.

21. Mukhopadhyay S, Basu D, Chakrabarti P. Characterization of a porin from Mycobacterium smegmatis. J Bacteriol. 1997;179:6205-6207.

22. World Health Organization. WHO guidelines for the treatment of Chlamydia trachomatis. World Health Organization 2016. Available at: http://apps.who.int/iris/bitstream /10665/246165/1/9789241549714eng.pdf . [Accessed on 05 Aug 2017].

23. Patel R, Green J, Clarke E et al. 2014 UK national guideline for the management of anogenital herpes. Int J STD AIDS. 2015; 26(11):76376.

24. Bignell C, Fitzgerald M; Guideline Development Group; British Association for Sexual Health and HIV UK. UK national guideline for the management of gonorrhoea in adults, 2011. Int J STD AIDS. 2011; 22(10):541-7.
25. Pittaway DE, Winfield AC, Maxson $\mathrm{W}$ et al. Prevention of acute pelvic inflammatory disease after hysterosalpingography: efficacy of doxycycline prophylaxis. Am J Obstet Gynecol 1983; 147: 623-626.

26. Chan KK, Tam KF, Tse KY, Ngan HY The use of vaginal antimicrobial after large loop excision of transformation zone: a prospective randomised trial. BJOG 2007; 114 (8): 970-6.

27. Kasius JC, Broekmans FJ, Fauser $\mathrm{BC}$ et al. Antibiotic prophylaxis for hysteroscopy evaluation of the uterine cavity. Fertil Steril 2011; 95: 792-794.

28. The Royal Australian and New Zealand College of Obstetricians and Gynaecologists (RANZCOG). Prophylactic antibiotics in obstetrics and gynaecology: 2016

Harmanli O, Boyer RL, Metz S, Tunitsky E, Jones KA. Doubleblinded randomized trial of preoperative antibiotics in midurethral sling procedures and review of the literature. Int Urogynecol J 2011; 22 (10): 124953. 